\title{
A ORGANIZAÇÃO METROPOLITANA PÓS-CONSTITUIÇÃ̃ DE 1988
}

\author{
Eduardo Fontes Hotz \\ Arquiteto, Presidente da Empresa Metropolitana de Planejamento da Grande São Paulo
}

\begin{abstract}
Resumo: Este artigo apresenta uma suscinta visão da organização regional após a promulgação da Constituição Federal de 1988 e seus reflexos no Estado de São Paulo: na Constituição Estadual, na sua legislação complementar e na criação, implantação e regularização de suas regiões metropolitanas.

Palavras-chave: regiões metropolitanas; constituições e metrópoles; gestão pública.
\end{abstract}

É fato conhecido que o ordenamento constitucional brasileiro, no que se refere à questão do desenvolvimento urbano, à qual a organização regional metropolitana é aspecto diretamente associado, tardou bastante em prover seu reconhecimento e habilitar instrumentos de intervenção correspondentes para seu enfrentamento.

O país teve, de sua Independência até a redemocratização após o período autoritário 1964-82, oito diplomas constitucionais.

Destes diplomas, o único, até a Carta de 1988, que deu ao fato urbano tratamento específico foi a Constituição Imperial de 1824. Dispôs esta, em seu art. 167, que: "Em todas as Cidades, e Villas ora existentes, e nas mais, que para o futuro se crearem haverá Camaras, às quaes compete o Governo economico, e municipal das mesmas Cidades, e Villas". E, no seu art. 169: "O exercício de suas funcções municipaes, formação de suas Posturas policiaes, applicação de suas rendas, e todas as suas particulares, e úteis attribuições, serão decretadas por uma Lei regulamentar".

Esta lei foi efetivamente promulgada em $1^{\circ}$ de outubro de 1828 , dispondo, entre variada matéria relativa à organização municipal, em seu art. 66, no âmbito do Título III - Posturas Policiaes, que as cidades e vilas: "Terão a seu cargo tudo quanto diz respeito à polícia, e economia das povoações, e seus termos, pelo que tomarão deliberações, e proverão por suas posturas sobre os objetos seguintes:
(...) alinhando, no rol destes, doze competências, desde a referente a 'Alinhamento, limpeza, iluminação, e desempachamento das ruas, cáes e praças (...)' e matérias correlatas à autorização de 'espectaculos públicos nas ruas, praças e arraiaes." "É perceptível, no texto, a cobertura especificada de todas as funções correspondentes a competências para atuação do poder público junto às cidades e outras categorias de aglomerados urbanos.

Os textos constitucionais republicanos, do primeiro, de 1891, até o de 1969 , deixaram de proceder à enumeração detalhada das competências atinentes ao trato da cidade, optando pela formulação, um tanto genérica, de que aos municípios ficasse assegurada sua autonomia "em tudo quanto respeite ao seu peculiar interesse" (Carta de 1891, Art. 69).

As Cartas de 1934 a 1946 mantêm o conceito do "peculiar interesse" local, acrescentando à formulação geral deste cláusulas como: "a organização dos serviços de sua competência" (Carta de 1934, Art. 13, Inc. III); "a organização dos serviços públicos de caráter local" (Carta de 1937, Art. 26, Inc. III); “(...) administração própria, no que concerne ao seu peculiar interesse e, especialmente (...) à organização dos serviços públicos locais" (Carta de 1946, Art. 28, Inc. II, Al. b). As Constituições autoritárias de 1967 e 1969 (Emenda no 1) praticamente repetem a formulação da Carta de 1946 (Art. 16, Inc. II, Al. b, texto de 1967; Art. 15, Inc. II, Al. b, texto de 1969). 
Nos diplomas republicanos até 1969 , são comuns a ausência de menção específica sobre as cidades ou outros tipos de urbanizações, a limitação do uso da expressão "urbano" apenas para a caracterização dos tributos desta espécie, por conta dos municípios, e a não-inclusão de qualquer cláusula a respeito de competências dos Estados federados e da União quanto às redes urbanas. Esse fato, entre outros, levou, ao longo do prazo de vigência das Cartas Republicanas entre 1891 e 1987, à afirmação de que, embora fosse o Brasil um país predominantemente urbano, sua legislação não o reconhecia como tal.

As Cartas autoritárias de 1967-69 foram, de fato, as primeiras, no período republicano, a expressar concretamente o reconhecimento da existência do fenômeno urbano e da competência do poder público para atuar junto ao mesmo. Porém, de maneira um tanto curiosa e paradoxal, o fato urbano reconhecido nesses diplomas corresponde a uma superestrutura urbana (a Região Metropolitana), enquanto as estruturas básicas da urbanização não são objeto de qualquer inovação no tratamento jurídico tradicional das Cartas da República.

As formulações sobre regiões metropolitanas, na Carta de 1967 e em sua Emenda de 1969, têm teores bastante semelhantes: o texto de 1967 inclui as disposições sobre aquelas regiões em seu título III - DA ORDEM ECONÔMICA E SOCIAL, através do Art. 157, § 10, com enunciado "A União, mediante lei complementar, poderá estabelecer regiões metropolitanas, constituídas por Municípios que, independentemente de sua vinculação administrativa, integrem a mesma comunidade sócio-econômica, visando à realização de serviços de interesse comum"; a Carta de 1969, em título idêntico ao de 1967, coloca a figura jurídica das regiões metropolitanas e disposições a respeito das mesmas em seu Art. 164, com enunciado: "A União, mediante lei complementar, poderá, para a realização de serviços comuns, estabelecer regiões metropolitanas, constituídas por municípios que, independentemente de sua vinculação administrativa, façam parte da mesma comunidade sócio-econômica".

Verifica-se, na leitura destes textos, que o legislador do autoritarismo tratou de circunscrever o fato metropolitano, do ponto de vista da autoridade, à União, único poder autorizado a instituir unidades regionais da espécie e, do ponto de vista do alcance da ação metropolitana, apenas à realização de serviços de interesse comum, deixando de lado outras categorias que poderiam conotar esta ação.

$\mathrm{Na}$ esteira dos ditames constitucionais da década de 60 , foram criadas as primeiras nove regiões metropolitanas do país - São Paulo, Belém, Belo Horizonte, Curitiba, Fortaleza, Porto Alegre, Recife, Rio de Janeiro e Salvador -, bem como regulamentado seu funcionamento (Leis Federais Complementares $\mathrm{n}^{\circ} 14$, de 8 de junho de 1973, ${ }^{1}$ e $\mathrm{n}^{\circ} 27$, de 3 de novembro de $1975,{ }^{2}$ e a Lei Complementar Estadual no 94 , de 29 de maio de $1974^{3}$ ). Através destes diplomas, estabeleceu-se um formato de gestão daquelas regiões, comportando dois Conselhos: um Deliberativo e outro Consultivo.

A composição final adotada para os dois Conselhos traduziu uma presença hegemônica dos Executivos estaduais na gestão metropolitana. No caso do Deliberativo, estipulou-se uma composição total de seis membros, nomeados pelo governador do Estado, devendo um, dentre os mesmos, ser indicado a partir de lista tríplice organizada pelo prefeito da capital e outro, pelos demais municípios integrantes da unidade regional. Ficava, assim, o Conselho dotado de maior poder, já que encarregado das deliberações (abstraídas quaisquer outras considerações colaterais pela base) sob a hegemonia do Estado - assegurada pelo estatuto -, uma vez que era representado por quatro membros, num total de seis.

O outro Conselho, de poder necessariamente mais reduzido, dada a sua característica consultiva, era composto pelo prefeito, ou seu representante, de cada um dos municípios contemplados na circunscrição da Região, sob a direção do presidente do Conselho Deliberativo.

Com essas feições, os formatos de gestão definidos logo passaram a ser acusados de centralizadores e pouco representativos das realidades políticas regionais, pela dependência da criação das unidades por meio de lei complementar federal e pela hegemonia dos Executivos estaduais na gestão.

Outrossim, patentearam-se sérias dificuldades na vinculação entre as decisões dos Conselhos Deliberativos e as orientações externadas pelos Consultivos e, da mesma forma, entre as ações dos diferentes agentes setoriais nas regiões e as orientações traçadas pelo Conselho Deliberativo. As próprias deliberações apresentaram problemas para serem alcançadas nas reuniões desses conselhos, dadas as dificuldades encontradas pelos representantes do Estado para se articularem livremente e negociarem, no bom e público sentido dessa palavra, seus interesses e posicionamentos naqueles plenários, sem o risco de desgastes em suas imagens e posturas públicas. Prevaleceu, em conseqüência, um claro esvaziamento das reuniões e da freqüência destas, no caso de ambos os Conselhos, bem como a prática de acertos prévios entre os representantes do Estado integrantes do Deliberativo quanto às matérias a votar. 


\section{A CONSTITUIÇÃO FEDERAL DE 1988}

Assim, ao ensejo dos debates que antecederam a elaboração da Carta Constitucional de 1988, ficava patenteada a falência dos formatos institucionais disponíveis para a organização regional, em âmbito metropolitano no país, bem como a necessidade de se proceder à sua substituição.

Deve-se reconhecer que a Constituição de 1988 prestou-se muito bem ao atendimento dessa necessidade. Desde logo, em suas formulações mais gerais, adotou conceitos e princípios que, embora indiretamente, favoreceram a possibilidade da organização regional no país. Entre estes, cabe destacar:

- a alçada do município à posição de integrante do pacto federativo, portanto, em condições de se organizar, por Carta própria, a Lei Orgânica Municipal, não mais como antes, outorgada pelo Estado federado, mas sim promulgada, à feição de um texto constitucional, pelo Legislativo local (Arts. $1^{\circ}$ e 29 );

- conceito do federalismo de cooperação, traduzido especificamente na redistribuição do quadro de competências entre os três níveis de governo, com a previsão de que certas matérias sejam tratadas por mais de um nível, cabendo à União a competência normativa geral, aos Estados federados competências intermediárias, em parte normativas, em parte de execução, e ao município a execução; ensejou-se, assim, a perspectiva concreta de uma organicidade maior na atuação dos três níveis, de cuja necessidade, há muito, a Administração se ressentia no país (Arts. 21, 22, 23 e 24);

- reconhecimento do Estado como agente normativo e regulador da atividade econômica, em condições de exercer, na forma da lei, as funções de fiscalização, incentivo e planejamento, sendo este determinante para o setor público e indicativo para o privado (Art. 174).

Quanto à temática específica do desenvolvimento urbano, a Carta também inovou, em relação às suas predecessoras, através de disposições, tais como:

- reconhecimento da realidade urbana como fenômeno a ser objeto da ação de governo, com a cominação expressa, em âmbito municipal, de se responsabilizar pela política urbana, obedecidas normas gerais a serem baixadas, em princípio, pelo nível federal (Arts. 21, Inc. XX; 24, Inc.I; 30, Inc. VIII);

- a definição de instrumentos a serem acionados pelo poder público municipal na defesa e manutenção da função social da propriedade urbana (Art. 182);
- reconhecimento do Plano Diretor como instrumento básico da política de desenvolvimento e expansão urbana e sua obrigatoriedade para cidades com mais de 20 mil habitantes (Art. 182, § $1^{\circ}$ ).

No aspecto das regiões metropolitanas, também o texto constitucional de 1988 aportou substanciais inovações. Por um lado, fez do Estado federado o titular da criação, por lei complementar, das unidades regionais, atendendo à critica sobre o excesso de centralização presente no estatuto anterior (Art. 25, $\S 3^{\circ}$ ). Por outro, ampliou o número de figuras correspondentes às unidades regionais, formalizando as categorias das aglomerações urbanas e microrregiões (mesmos Art. e $\S$ citados). Esta disposição mostrou-se de grande utilidade, no sentido de propiciar a organização regional em qualquer parte do país que o requeira, sem a necessidade, que acabaria por se constituir num bloqueio, de que essa organização só se pudesse dar com o uso da figura região metropolitana. Tornou-se possível, assim, reservar, para a qualificação dentro desta categoria, apenas aquelas regiões dotadas de funções e estruturação claramente metropolitanas.

O texto substituiu, também, a figura reducionista da finalidade a que se destina a organização regional, conforme colocada no estatuto anterior, ampliando-a e conferindo-lhe maior rigor conceitual na formulação "para integrar a organização, o planejamento e a execução de funções públicas de interesse comum" (Art. 25, § $3^{\circ}$ ).

\section{A CONSTITUiÇÃo ESTADUAL DE 1989}

As disposições inovadoras assim incluídas no texto da Carta Magna de 1988 repercutiram nas Cartas estaduais promulgadas em 1989. A Constituição paulista, em especial, incluiu todo o Capítulo II, em seu Título IV - Dos Municípios e Regiões - intitulado Da Organização Regional. Nesse capítulo, procedeu-se à definição de objetivos visados com aquela organização, dos requisitos que configurariam os três tipos previstos de unidade regional e se estabeleceram formatos básicos para a gestão regional, os quais prevêem que a unidade contará com um Conselho de caráter normativo e deliberativo, no qual os municípios integrados na região, em seu conjunto, terão paridade nas votações em relação ao Estado. O texto da Carta de São Paulo estipulou, ainda, que o Conselho previsto, no caso de região metropolitana, deve integrar entidade pública de caráter territorial, à qual estariam vinculados os órgãos de direção e execução, bem como as entidades regionais e setoriais executoras das funções públicas de 
interesse comum, no tocante ao planejamento e medidas para sua implementação.

A Carta paulista incluiu, ainda, em suas disposições, as compatibilizações recíprocas - a serem buscadas nas unidades regionais - entre as programações dos governos estadual e municipal, a garantia da participação da população no processo de planejamento e tomada de decisões e na fiscalização da realização dos serviços e funções públicas em âmbito regional e, por fim, a cominação ao Estado, em conjunto com os municípios integrantes de regiões metropolitanas, da responsabilidade pelo planejamento do transporte coletivo de caráter regional.

Não resta dúvida de que este conjunto de inovações vem possibilitar uma gestão regional e metropolitana à altura do significado mais poderoso e legítimo do princípio da organização regional. Este deve ser entendido em seu significado mais abrangente e rigoroso, fugindo dos estereótipos com que, por vezes, vem caracterizado como mero arranjo institucional, de caráter pragmático, para resolver problemas determinados. $\mathrm{Ou}$, de forma equivocada, para tratar de assuntos que, supostamente, não tenham esse tratamento previsto no quadro das competências dos três níveis de governo instituídos no país. Uma compreensão correta no plano teórico, e com potencial de eficácia na orientação da ação a ser desenvolvida junto às unidades regionais, não pode enveredar por esses rumos, através de visões impressionistas e de senso comum, as quais, com freqüência, reputam a instituição de um hipotético "quarto poder", de natureza regional, como a única solução para a eficácia da ação nas regiões.

É preciso que se tenha presente que, segundo o ordenamento institucional vigente no país, todas as competências para a ação do poder público já se acham distribuídas pelos três níveis governamentais não de forma aleatória, mas sim de maneira intencionalmente estruturada, essencial à sustentação e continuidade do modo de produção pelo qual o Brasil historicamente optou: o da economia de mercado, com base na livre iniciativa e na propriedade privada dos meios de produção.

Se assim entendida a distribuição de competências entre os três níveis, será clara a percepção de que: à União foram cominadas privativamente as que incidem sobre o processo de acumulação; em caráter compartilhado com os Estados federados, as referentes à reprodução do modo de produção e à produção dentro deste; e, de forma normativa geral, alguma que diz respeito à reprodução coletiva da força de trabalho. Ficará igualmente claro que o Estado federado, juntamente com a União, tem, como suas competências, aquelas ligadas à reprodução do modo, à produção dentro deste e, já de forma mais acentuada, alguma com efeitos na reprodução coletiva da força de trabalho. Porém, é ao município que, essencialmente, estarão cominadas as competências ligadas a essa categoria econômico-política.

Uma vez explicitada a repartição de competências entre os níveis de governo, com seus significados correspondentes, será imediata a compreensão de que não há margem para uma competência especificamente regional que justificasse a emergência de um quarto poder, o qual, caso instituído, nada mais seria do que um supermunícipio ou um subestado. Também chega-se ao entendimento - útil para o desvendamento da real natureza da ação regional de que tudo aquilo que se faz no âmbito público, estando esta presente, não deixa de ser feito, se tal não ocorrer. Apenas existindo a ação regionalizada, tudo o que se faz naquele âmbito far-se-á melhor com superior aproveitamento de fatores e recursos disponíveis e, principalmente, com maior qualidade política e legitimidade social, residindo esta última precisamente na necessidade - que com a ação regional fica criada - de os interesses hegemônicos da acumulação, da reprodução do modo e da produção dentro deste negociarem, no bom e público sentido dessa palavra, com os interesses da população, em sentido geral, correspondentes à reprodução coletiva da força de trabalho.

Se assim entendido o "fazer regional", estará impresso a este o caráter efetivamente político que o pode conotar, alargando o espectro com o qual o entendimento jurídico corrente visualiza essa expressão: a da capacidade de legislar.

Formando e encaminhando, para a execução pelos três níveis de poder, decisões de qualidade e poupadoras de recursos, fazendo bom uso dos fatores de desenvolvimento presentes e propiciando um balanceamento mais eqüitativo entre os determinantes ligados aos interesses hegemônicos e os que, no quadro social presente, aparecem sempre em posição secundária, a ação e a organização regionais terão atingido seu efetivo papel político e sua razão de existir.

\section{LEIS COMPLEMENTARES À CONSTITUIÇÃO ESTADUAL DE 1989}

\section{Lei Complementar $n^{\circ}$ 760, de 01 de agosto de 1994}

Buscando o "fazer regional" associativo, conforme propiciado pelas Cartas federal e paulista, houve por bem 
a Assembléia Legislativa propor e o governador sancionar Lei Complementar, de número 760 , de $1^{\circ}$ de agosto de 1994. Esta lei teve por objetivo "regulamentar a Divisão Regional no Estado de São Paulo" e passou a condicionar os demais instrumentos legais que vieram a ser promulgados, referentes à criação de regiões metropolitanas no âmbito estadual.

A referida lei complementar disciplinou as condições nas quais se dão as relações entre os poderes envolvidos, as entidades públicas a constituir o sistema de gestão regional, bem como definiu a forma pela qual se estabelecerá a participação da população no processo da gestão metropolitana.

A partir do Conselho, de caráter normativo e deliberativo, que no caso das regiões metropolitanas deverá integrar entidade pública de caráter territorial, a Lei Complementar $n^{\circ} 760 / 94$ definiu também as exigências para a instalação do Fundo de Desenvolvimento e da Agência de Desenvolvimento, ambos com a mesma territorialidade operacional do Conselho, estabelecendo as respectivas funções e as características técnicas e administrativas, bem como definindo que a representação da população será estabelecida pelo Conselho de Desenvolvimento, em seu regimento interno.

Ao mesmo tempo, a lei estabeleceu que a representação no Conselho de Desenvolvimento Metropolitano seja feita, como determina a Constituição do Estado, pelos prefeitos dos municípios da região, paritariamente com os representantes do Estado, naquelas funções públicas de interesse comum, as quais a própria Lei Complemen$\operatorname{tar} n^{\circ} 760$ instituiu, permitindo, no entanto, que o Conselho de Desenvolvimento defina outras a partir de suas próprias necessidades.

Assim, ao ficar definido que o Conselho deve ser composto por prefeitos (ou seus representantes e suplentes) e representantes do Estado, limitou-se a representação, segundo a interpretação corrente, apenas a esses dois segmentos da sociedade, remetendo a participação da população, entidades civis, sociais, legislativos municipais e outros que, porventura, possam se candidatar a uma representação popular ao âmbito de decisão do regimento interno dos Conselhos de Desenvolvimento.

Com esse espírito, foram então apreciados os projetos que sucederam a Lei Complementar $n^{\circ} 760 / 94$, visando instituir as Regiões Metropolitanas da Baixada Santista e de Campinas - criadas, elas também, por Leis Complementares - que serão a seguir apreciadas.

\section{A REGIÃO METROPOLITANA DA BAIXADA SANTISTA}

A Região Metropolitana da Baixada Santista (RMBS) foi criada pela Lei Complementar $n^{\circ} 815$, de 30 de julho de 1996, que estabelecia a região metropolitana e seu sistema de gestão, autorizando a instalação do Conselho de Desenvolvimento e a criação do Fundo Metropolitano e da Agência de Desenvolvimento Metropolitano, os quais tinham suas características funcionais, administrativas, de pessoal e de inter-relacionamento estabelecidas no texto desta lei, tendo sido instalado o Conselho de Desenvolvimento da Baixada Santista, em novembro de 1996, pelo governador do Estado.

A implantação da RMBS foi conduzida pela Secretaria de Transportes Metropolitanos, enquanto os estudos técnicos e institucionais que antecederam sua criação foram elaborados pela Secretaria de Economia e Planejamento.

Instalado o Conselho, desenvolveram-se as atividades básicas de aprovação do Regimento Interno do Conselho, da implantação da Secretaria Executiva do mesmo - conduzida provisoriamente pela Emplasa, órgão de planejamento metropolitano do Estado e da Secretaria de Transportes Metropolitanos, até a instalação da Agência -, da aprovação do Regimento das Câmaras Temáticas do Conselho e de suas respectivas criações e instalações.

O Fundo Metropolitano, cuja autorização de criação estava prevista na Lei Complementar n ${ }^{\circ} 815 / 96$, foi regulamentado pelo Decreto $\mathrm{n}^{\circ} 42.833$, de 28 de janeiro de 1998 , tendo sido imediatamente indicado o seu presidente e constituído o seu Conselho de Orientação.

A Agência de Desenvolvimento Metropolitano, também prevista na Lei Complementar $n^{\circ} 815 / 96$, foi criada pela Lei Complementar no 853 , de 23 de dezembro de 1998, tendo processo de instalação em condições operacionais até abril de 2000, quando assumiu integralmente as atividades de suporte técnico e administrativo do sistema de gestão da RMBS, ocasião em que a Emplasa afastou-se de suas atividades de apoio ao Conselho de Desenvolvimento.

O processo de implantação do sistema de gestão da RMBS será objeto de comentários posteriores, porém, cumpre assinalar que, graças à experiência adquirida neste processo, foi possível enriquecer as proposições, no âmbito da Lei Complementar $n^{\circ} 760 / 94$, no que se refere ao sistema de gestão e seus elementos componentes. 


\section{A REGIÃO METROPOLITANA DE CAMPINAS}

No caso dos estudos para a criação da Região Metropolitana de Campinas, conduzidos pela Secretaria de Economia e Planejamento, foi possível avançar na forma da representação da população, através da proposição de um segundo conselho, de caráter consultivo, para abrigar a participação dos legislativos municipais e cujos demais componentes serão definidos no regimento interno do Conselho de Desenvolvimento, bem como sua forma operacional.

Isto está contido na Lei Complementar $\mathrm{n}^{\circ} 870$, sancionada pelo governador, em 19 de junho de 2000, lei esta que, com a finalidade de criação da Região Metropolitana de Campinas, autoriza também a instituição de seu sistema de gestão composto, além do Conselho de Desenvolvimento Metropolitano de Campinas, do respectivo Fundo Metropolitano, da Agência de Desenvolvimento e do referido Conselho Consultivo.

No caso particular dessa região metropolitana, ainda não foi instituído o seu Conselho de Desenvolvimento, o que deverá ocorrer no início de 2001, a partir do qual serão encaminhadas as providências complementares para a criação dos demais elementos do sistema de gestão metropolitana regional, conforme citados anteriormente.

\section{A REGIÃo METROPOLITANA dE SÃO PAULO}

Constituída em 1974, a Região Metropolitana de São Paulo (RMSP) está em situação bastante peculiar, já que os elementos componentes de seu sistema de gestão encontram-se em desacordo com as atuais regras legais, devendo, portanto, ser objeto de uma nova regulamentação.

A complexidade e a dimensão da RMSP, com seus 39 municípios, exigem uma reflexão mais apurada sobre a operacionalidade de qualquer sistema de gestão que se organize sobre tão grande extensão territorial. Nos seus 26 anos de existência, a região tem sido objeto de inúmeros e significativos estudos de abordagem setorial, global ou de aspectos sub-regionais, consolidando, estes últimos, uma visão de grupos municipais articulados em torno de centros complementares à dinâmica metropolitana do centro tradicional. Ao longo do tempo, foi possível estabelecer uma sub-regionalização com grandes proveitos operacionais e estratégicos.

Essa sub-regionalização, que tem na capital paulista, considerada sub-região centro, o próprio município irradiador da metropolização, limítrofe a todas as demais, compõe-se de outras seis sub-regiões, nas quais os eventos de impacto metropolitano têm sua concentração acentuada por características locais de proximidade e integração.

Embora não prevista na lei, a sub-regionalização já é um fato. A sub-região sudeste do Grande $A B C D$, reunindo sete municípios, tem se constituído em um pólo dinâmico de debates e experiências sub-regionais em relação à RMSP. Da mesma forma caminham as sub-regiões oeste e sudoeste, ao criarem seu Fórum Regional, buscando integrar as iniciativas do poder local, público e privado, do social e do econômico, para constituírem alternativa de debate às estruturas institucionais vigentes.

Como essas três sub-regiões, as demais necessitam desses instrumentos de aproximação da sociedade com o governo, a fim de se otimizarem as ações públicas e privadas nos campos sociais e econômicos, de forma a serem valorizadas as comunidades locais nas ações de consolidação do desenvolvimento sub-regional, compatível com as potencialidades de cada uma das partes componentes da RMSP.

Neste sentido, seria indesejável que o sistema de gestão metropolitano da RMSP ignorasse tais potencialidades na legislação que propusesse sua reorganização. Para tanto, um estudo preliminar, elaborado pela Secretaria dos Transportes Metropolitanos, a quem compete a condução da gestão metropolitana de São Paulo, foi oferecido à Secretaria de Economia e Planejamento, buscando potencializar as oportunidades de planejamento sub-regional e incorporando as experiências locais, sem que com isto fosse alterado o modelo de gestão definido pela legislação vigente.

Tal proposta tem, entre outras características, a de permitir:

- a manutenção da conformação tradicional da RMSP, até que novos estudos comprovem necessidade de ações complementares;

- a abordagem sub-regional das questões metropolitanas, facilitando seus tratamentos de acordo com as realidades locais;

- a incorporação das experiências já realizadas pelos municípios ou grupo de municípios com problemas comuns já integrados;

- o aproveitamento das estruturas institucionalizadas nos processos locais de tratamento de questões comuns, desde que observadas as condições mínimas exigidas pela legislação vigente;

- a racionalização dos processos de decisão referentes às questões metropolitanas, partindo do sub-regional para o 
regional, cabendo às instâncias metropolitanas do sistema de gestão o estabelecimento de diretrizes e a aprovação dos programas metropolitanos de desenvolvimento, ouvidas as unidades sub-regionais;

- a valorização da ação local, sub-regional, ampliando-se as oportunidades de incorporação das comunidades locais em definir seus próprios projetos de desenvolvimento.

Tais proposições, factíveis no bojo de um projeto de gestão metropolitana compatível com as legislações vigentes, não implicariam a alteração do modelo institucional proposto para as regiões metropolitanas, exigindo apenas uma dedicação maior das entidades envolvidas: Conselho de Desenvolvimento Metropolitano; Fundo Metropolitano; e Agência de Desenvolvimento, com os aspectos de suporte institucional, administrativo e técnico na articulação das decisões locais quanto à compatibilidade com os planos e projetos metropolitanos.

\section{PAUTAS DE INTERESSE DAS REGIÕES METROPOLITANAS}

Primeiramente, é necessário renovar a necessidade do estabelecimento de políticas nacionais para o desenvolvimento urbano e metropolitano brasileiro.

Tais políticas permitiriam que as ações da União se desenvolvessem com maior articulação entre destinação de recursos, objetivos de desenvolvimento regional e prioridades de desenvolvimento estratégico nacional. Possibilitariam ainda que estados e municípios se articulassem em torno de metas comuns, otimizando recursos e tempo, por meio de maior mobilização social resultante da participação das comunidades, da população, nas definições de suas ações locais, sub-regionais.

Em segundo lugar, é necessário que os Estados estruturem suas políticas de desenvolvimento regional, urbano e metropolitano, de forma a se capacitarem para intervir sobre os respectivos territórios, com os instrumentos disponíveis pelo conhecimento, pela ciência e pela tecnologia, ultrapassando a fase de ações superficiais, tópicas ou sintomáticas, substituindo-as pelo planejamento estratégico voltado para o desenvolvimento sustentável, com a participação organizada e responsável da sociedade civil, da iniciativa privada e dos representantes do poder público, em associação que permita que a gestão de governo seja cada vez mais "gestão compartilhada" entre níveis de governo, entre governo e iniciativa privada, entre governo e representações sociais, entre iniciativa privada e representações sociais.
Em terceiro lugar, é necessário que se envidem esforços de mobilização, coordenação e promoção de conhecimento sobre os fenômenos urbanos e metropolitanos, segundo suas formas de ocupação do território, na nova fase de desenvolvimento da economia globalizada, com impactos em países como o Brasil, especialmente em suas metrópoles e cidades menores, pela integração do serviço público com os centros de ensino e pesquisa e com as preocupações da iniciativa privada como forma de a sociedade se antecipar aos estrangulamentos a investimentos produtivos ou às deseconomias de escala resultantes de investimentos cujos impactos não foram levados adequadamente em consideração.

Em quarto lugar, cumpre destacar, como pautas regionais, aquelas que privilegiem enfoques agregados, em especial:

- a competitividade regional, pela mudança de requisitos na economia globalizada, que exige mão-de-obra qualificada, infra-estrutura de energia, transportes e comunicações, base científica e tecnológica, existência de setores de alta tecnologia, produtos diferenciados para mercados segmentados, economia de escala e presença de aglomerados (cadeias produtivas) concentrados geograficamente;

- o apoio à reconversão regional mediante readaptação das estruturas regionais, em face das mudanças nas bases econômica e tecnológica, visando a superação da obsolescência tecnológica, a requalificação da mão-de-obra, a adequação dos requisitos de infra-estrutura e a preservação do meio ambiente e readaptação do ambiente construído;

- criação e difusão de conhecimentos;

- melhoria nos níveis de eqüidade e redução da exclusão social mediante ampliação da renda mínima, acesso a empregos formais, acesso à cultura, à moradia e à mobilidade, redução da violência e melhoria do meio ambiente e da qualidade de vida em geral.

Finalmente, deve ser lembrado o incentivo à continuidade dos programas e projetos de desenvolvimento. Para tanto, são indispensáveis, de um lado, a participação de toda a sociedade e, de outro, a institucionalização de normas e condutas que viabilizem legalmente a continuidade desejada.

\section{CONCLUSÃo}

Deve-se destacar que o futuro imediato, para não dizer o presente, será o reino do urbano e do metropolitano, com mais de $90 \%$ da população brasileira residindo em cidades, das quais $10 \%$ abrigarão $80 \%$ do total da população urbana do país. 
O desafio de gerir tal dimensão de problemas e conflitos é o desafio que se afigura como central para o século XXI, que só poderá ser superado se lograr condições de investir em:

- capacitação, racionalidade e competência da administração pública;

- integração das forças sociais nos projetos de desenvolvimento;

- estabelecimento de projetos compartilhados e motivadores;

- desenvolvimento de práticas de gestão compartilhada governo com governo e governo com sociedade;

- aprimoramento da infra-estrutura de informações para a produção de planejamento estratégico;

- desenvolvimento da qualificação técnica, política e administrativa dos gestores públicos;
- consolidação dos princípios de cidadania como atributos de qualidade individual, social, empresarial, pública e privada.

\section{NOTAS}

Colaboraram neste artigo: Eloisa Raymundo Holanda Rolim, Mário Antônio F. Barreiros, Sérgio Zaratin.

1. Estabelece as Regiões Metropolitanas de São Paulo, Belo Horizonte, Porto Alegre, Recife, Salvador, Curitiba, Belém e Fortaleza.

2. Altera a redação do artigo $2^{\circ}$ da Lei Complementar $n^{\circ} 14$, de 8 de junho de 1973.

Art. $1^{\circ}$. O artigo $2^{\circ}$ ("caput") e seu $\S 1^{\circ}$ da Lei Complementar $n^{\circ} 14$, de 8 de junho de 1973, passam a vigorar com a seguinte redação:

"Art. $2^{\circ}$. Haverá em cada região metropolitana um Conselho Deliberativo, presidido pelo Governador do Estado, e um Conselho Consultivo, criados por lei estadual. $\S 1^{\circ}$ - O Conselho Deliberativo contará em sua composição, além do Presidente, com 5 (cinco) membros de reconhecida capacidade técnica ou administrativa, um dos quais será o Secretário-Geral do Conselho, todos nomeados pelo Governador do Estado, sendo um deles dentre os nomes que figurem em lista tríplice organizada pelo Prefeito da Capital e outro, mediante indicação dos demais municípios integrantes da região metropolitana.

3. Dispõe sobre a Região Metropolitana de São Paulo. 